\title{
PENGARUH PELATIHAN (TRAINING) DAN MOTIVASI KERJA TERHADAP KINERJA (PERFORMANCE) KARYAWAN DI PT KREASIJAYA ADHIKARYA
}

\author{
Fitra $^{1}$, Tia Ulfah Yurika Gultom ${ }^{2}$ \\ 1)Program Studi Teknik Industri, Sekolah Tinggi Teknologi Dumai \\ Jl. Utama Karya Bukit Batrem II \\ Email: fiet_fiet82@yahoo.co.id
}

\begin{abstract}
ABSTRAK
Pelatihan yang diberikan bisa membangun dan mengembangkan potensi karyawan, serta menambah pengetahuan. Melalui pelatihan akan memberikan jaminan bagi peningkatan kinerja karyawan pada pekerjaan yang dihadapi sekarang, maka pelatihan diarahkan untuk membantu karyawan menunaikan pekerjaan mereka secara lebih baik. Karyawan juga membutuhkan motivasi dalam melakukan pekerjaan baik sebagai pendorong atau penggerak secara internal maupun eksternal yang membuat karyawan bekerja secara optimal untuk mencapai tujuan perusahaan. Untuk meningkatkan kinerja karyawan di PT Kreasijaya Adhikarya, pelatihan karyawan dan motivasi kerja menjadi hal yang penting dalam mempengaruhi kinerja (performance) karyawan.

Berdasarkan dari permasalahan tersebut, penulis melakukan penelitian dengan menggunakan metode kuantitatif dan alat analisis regresi linier berganda dengan bantuan software statistik SPSS versi 24. Penggunaan regresi linier berganda untuk mengetahui pengaruh pelatihan dan motivasi kerja terhadap kinerja karyawan baik secara simultan maupun parsial.

Hasil penelitian menunjukkan bahwa secara simultan hanya motivasi kerja yang memiliki pengaruh signifikan terhadap kinerja karyawan. Jika secara parsial, pelatihan tidak memiliki pengaruh yang signifikan terhadap kinerja karyawan. Sedangkan motivasi kerja memiliki pengaruh yang signifikan terhadap kinerja karyawan. Motivasi kerja dapat menjelaskan perubahan tingkat kinerja karyawan sebesar $13,8 \%$.
\end{abstract}

Kata-kunci: Kinerja Karyawan, Kuantitatif, Motivasi Kerja, Pelatihan, Regresi Linier Berganda

\begin{abstract}
Training provided can build and develop the potential of employees, and increase knowledge. Through training will provide assurance for the improvement of employee's performance on the work faced now, the training is directed to help employees perform their work better. Employees also need motivation in doing good work as a driver or a driver internally and externally that makes employees work
\end{abstract}

UNITEK. Vol. 10 No. 2 Juli - Desember 2017 | p-ISSN 2089-3957 | e-ISSN 2580-2585 
optimally to achieve corporate goals. To improve employee performance in PT Kreasijaya Adhikarya, employee training and work motivation are important in influencing employee performance.

Of the problems, the authors conducted research using quantitative methods and multiple linear regression analysis tools with the help of statistical software SPSS version 24. The use of multiple linear regression to determine the effect of training and work motivation on employee performance either simultaneously or partially.

The results showed that simultaneously only the work motivation that has a significant influence on employee performance. If partially, training does not have a significant effect on employee performance. While the work motivation has a significant effect on employee performance. Work motivation can explain changes in employee performance level of $13.8 \%$.

Keywords: Employee Performance, Multiple Linear Regression, Training, Quantitative, Work Motivation.

\section{PENDAHULUAN}

PT Kreasijaya Adhikarya merupakan perusahaan yang berada dalam satu manajemen yang sama dengan PT KLK Dumai, yang bergerak di bidang industri pengolahan minyak kelapa sawit. Disetiap perusahaan pastinya selalu ada manajemen SDM (Sumber Daya Manusia) yang menjadi salah satu syarat untuk suatu perusahaan berdiri. Departemen atau devisi yang mengatur manajemen SDM di PT Kreasijaya Adhikarya yaitu departemen HR (Human Resource) Recruitment \& Training Department. HR (Human Resource) Recruitment \& Training Department memiliki peranan penting didalam perusahaan yang bertugas untuk mengelola dan mengembangkan SDM, dalam hal ini termasuk perencanaan, pelaksanaan, pegawasan, dan pengembangan kualitas SDM.

Sebagaimana dikemukakan oleh Mangkunegara (2005), istilah kinerja berasal dari kata job performance atau actual performance (prestasi kerja atau prestasi sesungguhnya yang dicapai seseorang) yaitu hasil kerja secara kualitas dan kuantitas yang dicapai oleh seorang pegawai dalam melaksanakan tugasnya sesuai dengan tanggung jawab yang diberikan kepadanya (Susanty \& Baskoro, 2012). Dengan adanya pelatihan (training) karyawan dapat membantu meningkatkan kinerja (performance) karyawan di PT Kreasijaya Adhikarya. Sesuai dengan definisi menurut Yani (2012) pelatihan dan pengembangan bagi sumber daya manusia adalah suatu kegiatan untuk meningkatkan kapasitas sumber daya manusia agar bisa menjadi sumber daya yang berkualitas baik dari segi pengetahuan, keterampilan bekerja, tingkat profesionalisme yang tinggi dalam bekerja agar bisa meningkatkan kemampuan untuk mencapai tujuan-tujuan perusahaan dengan baik. Motivasi juga dapat membantu meningkatkan 
kinerja (performance) karyawan di PT Kreasijaya Adhikarya. Motivasi membicarakan tentang bagaimana cara mendorong semangat kerja seseorang, agar mau bekerja dengan memberikan secara optimal kemampuan dan keahliannya guna mencapai tujuan organisasi (Wahjosumidjo dalam Sunyoto, 2015). Untuk meningkatkan kinerja (performance) karyawan di PT Kreasijaya Adhikarya, pelatihan (training) karyawan dan motivasi kerja menjadi hal yang penting dalam mempengaruhi kinerja (performance) karyawan.

\section{METODE PENELITIAN}

Tempat penelitian dilakukan di PT Kreasijaya Adhikarya yang berlokasi di Jl. Datuk Laksamana, komplek Pelindo 1, Dumai-Riau. Waktu penilitian dilakukan pada bulan Maret-Agustus 2017 dengan jumlah sampel penelitian adalah 90 karyawan. Diagram alir penelitian dapat dilihat pada Gambar 1. Pendekatan kuantitatif yaitu pendekatan penelitian yang digunakan untuk meneliti pada populasi atau sampel tertentu, pengumpulan data, menggunakan instrumen penelitian, analisis data bersifat kuantitatif atau statistik, dengan tujuan untuk menguji hipotesis yang telah ditetapkan. Penelitian ini bermaksud untuk menjelaskan kedudukan variabel-variabel yang diteliti serta hubungan antara satu variabel dengan variabel lain (Aruan, 2013).

Peneliti menggunakan metode kuantitatif dan alat analisis regresi linier berganda dengan bantuan software statistik SPSS versi 24. Kuesioner sebagai instrumen penelitian yang terdiri dari 15 pernyataan untuk 3 variabel. Kuesioner yang dibuat menggunakan skala likert dimana angka 4 adalah sangat setuju, 3 adalah setuju, 2 adalah kurang setuju, dan 1 adalah tidak setuju. Regresi linier berganda digunakan untuk menganalisis seberapa jauh variabel yang mempengaruhi kinerja (performance) karyawan dapat menggunakan model regresi linier berganda, yang mana menjadi variabel bebas adalah pelatihan (X1) dan motivasi kerja (X2) sedangkan yang menjadi variabel terikat yaitu kinerja (performance) karyawan (Y). Hipotesis (dugaan) regresi linier berganda (Sujarweni, 2014) sebagai berikut:

$\mathrm{Ho}_{1}$ : Tidak ada pengaruh antara pelatihan dan motivasi kerja terhadap kinerja

karyawan secara simultan.

$\mathrm{Ha}_{1}$ : Ada pengaruh antara antara pelatihan dan motivasi kerja terhadap kinerja

karyawan secara simultan.

UNITEK. Vol. 10 No. 2 Juli - Desember 2017 | p-ISSN 2089-3957 | e-ISSN 2580-2585 
$\mathrm{Ho}_{2}$ : Tidak ada pengaruh antara pelatihan dan motivasi kerja terhadap kinerja karyawan secara parsial.

$\mathrm{Ha}_{2}$ : Ada pengaruh antara pelatihan dan motivasi kerja terhadap kinerja karyawan secara parsial.

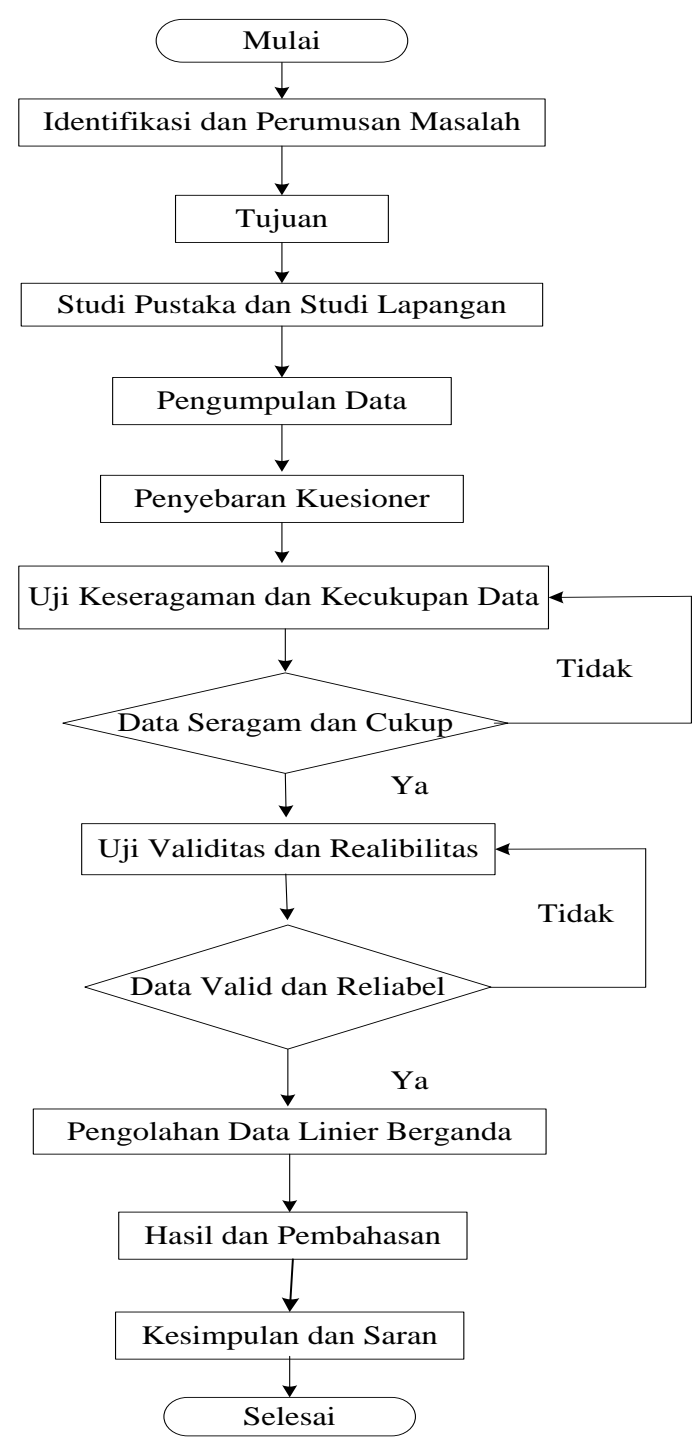

Gambar 1. Diagram Alir Penelitian 


\section{HASIL PEMBAHASAN}

\section{Pengumpulan Data}

Berdasarkan dari penelitian yang sudah dilakukan untuk mengetahui pengaruh pelatihan dan motivasi kerja terhadap kinerja karyawan di PT Kreasijaya Adhikarya. Didapatkan 90 kuesioner yang sudah di isi oleh 90 karyawan PT Kreasijaya Adhikarya.

\subsection{Karakterisitik Responden}

Data kuesioner yang sudah dikumpulkan pada saat penelitian di PT Kreasijaya Adhikarya, dapat diketahui karakteristik dari 90 responden. Klasifikasi responden berdasarkan gender (Jenis Kelamin) dapat di lihat pada Tabel 1.

Tabel 1. Klasifikasi Responden Berdasarkan Gender

\begin{tabular}{|c|c|c|c|}
\hline \multirow{2}{*}{ No } & \multirow{2}{*}{ Jenis Kelamin } & \multicolumn{2}{|c|}{ Jumlah Responden } \\
\cline { 3 - 4 } & & Angka & Persentase \\
\hline 1 & Laki-Laki & 83 & $92,22 \%$ \\
\hline 2 & Perempuan & 7 & $7,78 \%$ \\
\hline \multicolumn{2}{|c|}{ Jumlah } & 90 & $100 \%$ \\
\hline
\end{tabular}

Sumber: Pengolahan data, 2017

Tabel 1. Menunjukkan bahwa responden dalam penelitian ini lebih didominasi oleh responden laki-laki yaitu sebanyak 83 orang (92,22\%). Sedangkan responden perempuan sebanyak 7 orang (7,78\%). Klasifikasi responden berdasarkan tingkat pendidikan dapat di lihat pada Tabel 2.

Tabel 2. Klasifikasi Responden Berdasarkan Tingkat Pendidikan

\begin{tabular}{|c|c|c|c|}
\hline \multirow{2}{*}{ No } & \multirow{2}{*}{ Pendidikan } & \multicolumn{2}{|c|}{ Jumlah Responden } \\
\cline { 3 - 4 } & & Angka & Persentase \\
\hline 1 & SMA/SMK & 66 & $73,33 \%$ \\
\hline 2 & D3 & 6 & $6,67 \%$ \\
\hline 3 & S1 & 18 & $20,00 \%$ \\
\hline \multicolumn{2}{|c|}{ Jumlah } & 90 & $100 \%$ \\
\hline
\end{tabular}

Sumber: Pengolahan data, 2017

Tabel 2. menunjukkan bahwa ada 3 tingkatan pendidikan responden. Pendidikan responden yang terbanyak yaitu tingkat SMA sebanyak 66 responden (73,33\%). Tingkat pendidikan kedua yang terbanyak yaitu tingkat S1 sebanyak 18 responden (20,00\%). Sedangkan jumlah responden paling sedikit yaitu tingkat D3 sebanyak 6 responden (6,67\%). Klasifikasi responden berdasarkan usia dapat di lihat pada Tabel 3. 
Tabel 3. Klasifikasi Responden Berdasarkan Usia

\begin{tabular}{|c|c|c|c|}
\hline \multirow{2}{*}{ No } & \multirow{2}{*}{ Usia } & \multicolumn{2}{|c|}{ Jumlah Responden } \\
\cline { 3 - 4 } & & Angka & Persentase \\
\hline 1 & $20-25$ & 16 & $17,78 \%$ \\
\hline 2 & $26-30$ & 31 & $34,44 \%$ \\
\hline 3 & $31-35$ & 24 & $26,67 \%$ \\
\hline 4 & $36-40$ & 19 & $21,11 \%$ \\
\hline \multicolumn{2}{|c|}{ Jumlah } & 90 & $100 \%$ \\
\hline
\end{tabular}

Sumber: Pengolahan data, 2017

Tabel 3. diketahui bahwa usia responden yang terbanyak yaitu usia 26-30 tahun dengan jumlah responden sebanyak 31 orang (34,44\%). Usia responden terbanyak kedua yaitu usia 31-35 tahun (26,67\%). Usia responden terbanyak ketiga yaitu usia 36-40 tahun (21,11\%). Sedangkan usia responden yang paling sedikit yaitu usia $20-25$ tahun (17,78\%).

\section{Pembahasan}

\subsection{Uji Validitas dan Reliabilitas}

\section{Uji Validitas}

Hasil uji validitas terhadap butir pernyataan variabel pelatihan (X1), motivasi kerja (X2), dan kinerja karyawan (Y) dapat di lihat pada Tabel 4.

Tabel 4. Uji Validitas

\begin{tabular}{|c|c|c|c|c|}
\hline \multicolumn{5}{|c|}{ Uji Validitas } \\
\hline No & Variabel & Pernyataan & $\begin{array}{c}\mathrm{r} \\
\text { hitung }\end{array}$ & Keterangan \\
\hline \multirow{5}{*}{1} & \multirow{5}{*}{$\begin{array}{l}\text { Pelatihan } \\
\text { (X1) }\end{array}$} & $\mathrm{X} 1.1$ & 0,680 & Data Valid \\
\hline & & $\mathrm{X} 1.2$ & 0,598 & Data Valid \\
\hline & & $\mathrm{X} 1.3$ & 0,787 & Data Valid \\
\hline & & $\mathrm{X} 1.4$ & 0,738 & Data Valid \\
\hline & & $\mathrm{X} 1.5$ & 0,693 & Data Valid \\
\hline \multirow{5}{*}{2} & \multirow{5}{*}{$\begin{array}{c}\text { Motivasi } \\
\text { Kerja (X2) }\end{array}$} & $\mathrm{X} 2.1$ & 0,688 & Data Valid \\
\hline & & $\mathrm{X} 2.2$ & 0,599 & Data Valid \\
\hline & & $\mathrm{X} 2.3$ & 0,504 & Data Valid \\
\hline & & $\mathrm{X} 2.4$ & 0,634 & Data Valid \\
\hline & & $\mathrm{X} 2.5$ & 0,688 & Data Valid \\
\hline \multirow{5}{*}{3} & \multirow{5}{*}{$\begin{array}{c}\text { Kinerja } \\
\text { Karyawan } \\
\text { (Y) }\end{array}$} & Y.1 & 0,729 & Data Valid \\
\hline & & Y.2 & 0,616 & Data Valid \\
\hline & & Y.3 & 0,706 & Data Valid \\
\hline & & Y.4 & 0,798 & Data Valid \\
\hline & & Y.5 & 0,692 & Data Valid \\
\hline
\end{tabular}

Sumber: Pengolahan data, 2017 
Tabel 4. dapat diketahui nilai $\mathrm{r}$ hitung dari semua pernyataan variabel pelatihan (X1) yaitu 0,$680 ; 0,598 ; 0,787 ; 0,738 ; 0,693$; , motivasi kerja (X2) yaitu 0,$688 ; 0,599 ; 0,504 ; 0,634 ; 0,688$, dan kinerja karyawan $(\mathrm{Y})$ yaitu 0,729 ; 0,$616 ; 0,706 ; 0,798 ; 0,692$; memiliki data yang valid. Data dapat dikatakan valid jika $r$ tabel $<\mathrm{r}$ hitung. Nilai $\mathrm{r}$ tabel untuk 90 responden yaitu 0,174. Jadi $\mathrm{r}$ tabel $(0,174)<$ semua penyataan variabel $(\mathrm{X} 1, \mathrm{X} 2, \mathrm{Y})$, maka semua data valid.

\section{Uji Reliabilitas}

Hasil uji reliabilitas terhadap butir pernyataan variabel pelatihan (X1), motivasi kerja (X2), dan kinerja karyawan (Y) dapat di lihat pada Tabel 5 .

Tabel 5. Uji Reliabilitas

\begin{tabular}{|c|l|c|c|}
\hline \multicolumn{4}{|c|}{ Uji Reliabilitas } \\
\hline No & \multicolumn{1}{|c|}{ Variabel } & $\begin{array}{c}\text { Cronbach's } \\
\text { Alpha }\end{array}$ & Keterangan \\
\hline 1 & Pelatihan (X1) & 0,858 & Data Reliabel \\
\hline 2 & Motivasi Kerja (X2) & 0,738 & Data Reliabel \\
\hline 3 & Kinerja Karyawan (Y) & 0,859 & Data Reliabel \\
\hline
\end{tabular}

Sumber: Pengolahan data, 2017

Tabel 5. dapat diketahui nilai cronbach's alpha variabel pelatihan (X1) yaitu 0,858; dan variabel motivasi kerja yaitu 0,738; serta variabel kinerja karyawan yaitu 0,859. Data dapat dikatakan reliabel jika nilai cronbach's alpha $>0,60$. Nilai cronbach's alpha setiap variabel $>0,60$ maka semua data reliabel.

\subsection{Regresi Linier Berganda}

Uji regresi linier berganda terhadap variabel pelatihan (X1), motivasi kerja (X2), dan kinerja karyawan (Y) baik secara simultan ataupun parsial dapat di lihat pada Tabel 6 .

Tabel 6. Regresi Linier Berganda

\begin{tabular}{|c|c|c|c|c|c|}
\hline \multicolumn{7}{|c|}{ Regresi Linier Berganda (Method Forward) } \\
\hline No & Pengujian & Variabel & F & T & Sig. \\
\hline 1 & \multirow{2}{*}{ Simultan } & Motivasi Kerja (X2) & 14,048 & - & 0,000 \\
\hline \multirow{2}{*}{2} & \multirow{2}{*}{ Parsial } & Pelatihan (X1) & - & 1,933 & 0,056 \\
\cline { 3 - 6 } & & Motivasi Kerja (X2) & - & 3,748 & 0,000 \\
\hline
\end{tabular}

Sumber: Pengolahan data, 2017

Tabel 6. dilakukan pengambilan keputusan baik secara simultan dan parsial untuk menguji hipotesis yang sudah ada dengan persamaan linier berganda $\mathrm{Y}=9,233+0,434 \mathrm{X} 2$ sebagai berikut ini: 
1. Pengaruh antara pelatihan (X1) dan motivasi kerja (X2) terhadap kinerja karyawan (Y) secara simultan dimana $\mathrm{F}$ tabel (V1=k, V2=n-k-1,) jadi $(\mathrm{V} 1=2, \mathrm{~V} 2=87)=3,101$ (tabel $\mathrm{F}$ dengan alpha 5\%) dimana $\mathrm{F}$ hitung = 14,048. Jadi F hitung $>$ F tabel yaitu 14,048 > 3,101 dan signifikan 0,000 $<0,05$ maka Ho ditolak. Nilai signifikan dan $\mathrm{F}$ hitung hanya menunjukkan variabel motivasi kerja (X2). Maka secara simultan atau secara bersama-sama tidak ada pengaruh yang signifikan terhadap kinerja karyawan. Karena yang berpengaruh terhadap kinerja karyawan hanya motivasi kerja, sedangkan pelatihan tidak berpengaruh terhadap kinerja karyawan.

2. Pengaruh antara pelatihan (X1) dan motivasi kerja (X2) terhadap kinerja karyawan (Y) secara parsial.

a. Pengaruh pelatihan (X1) terhadap kinerja karyawan (Y) dimana t tabel $(\mathrm{df}=\mathrm{n}-1$ dengan $\mathrm{\alpha}=2,5 \%)=1,987$ dan $\mathrm{t}$ hitung $=1,933$ maka Ho diterima. Dengan sig 0,056 > 0,05 maka tidak terdapat pengaruh yang signifikan pelatihan (X1) terhadap kinerja karyawan (Y).

b. Pengaruh motivasi kerja (X2) terhadap kinerja karyawan (Y) dimana $\mathrm{t}$ tabel $(\mathrm{df}=\mathrm{n}-1$ dengan $\mathrm{a}=2,5 \%)=1,987$ dan $\mathrm{t}$ hitung $=3,748$ maka Ho ditolak. Dengan sig 0,000 $<0,05$ maka ada pengaruh yang signifikan motivasi kerja (X2) terhadap kinerja karyawan (Y).

\subsection{Uji Asumsi Klasik}

1. Multikolinieritas

Hasil uji mulitikolinieritas dapat di lihat pada Tabel 7.

Tabel 7. Uji Multikolinieritas

\begin{tabular}{|c|l|c|}
\hline \multicolumn{3}{|c|}{ Uji Multikolinieritas } \\
\hline No & \multicolumn{1}{|c|}{ Variabel } & VIF \\
\hline 1 & Pelatihan (X1) & 1,166 \\
\hline 2 & Motivasik Kerja (X2) & 1,000 \\
\hline
\end{tabular}

Sumber: Pengolahan data, 2017

Tabel 4.7. diketahui nilai VIF variabel pelatihan (X1) sebesar 1,166 dan motivasi kerja (X2) sebesar 1,000 masih berada diantara 1-10 jadi tidak terjadi multikolinieritas.

2. Autokorelasi

Hasil uji autokorelasi dapat di lihat pada Tabel 8. 
Tabel 8. Uji Autokorelasi

\begin{tabular}{|c|c|}
\hline \multicolumn{2}{|c|}{ Uji Autokorelasi } \\
\hline Variabel & $\begin{array}{c}\text { Durbin- } \\
\text { Watson }\end{array}$ \\
\hline $\begin{array}{c}\text { Pelatihan (X1), Motivasi } \\
\text { Kerja (X2), Kinerja } \\
\text { Karyawan (Y) }\end{array}$ & 1,663 \\
\hline
\end{tabular}

Sumber: Pengolahan data, 2017

Tabel 8. diketahui nilai d hitung yaitu 1,663 . Untuk nilai d tabel $(k, n)$ jadi (2,90) diperoleh nilai du dan dl adalah 1,703 dan 1,612. Maka nilai autokorelasi $\mathrm{dl}<\mathrm{d}<\mathrm{du}$ atau $1,612<1,663<1,703$ tidak menghasilkan kesimpulan yang pasti.

3. Heteroskedastisitas

Hasil uji heteroskedastisitas dapat di lihat pada Gambar 2.

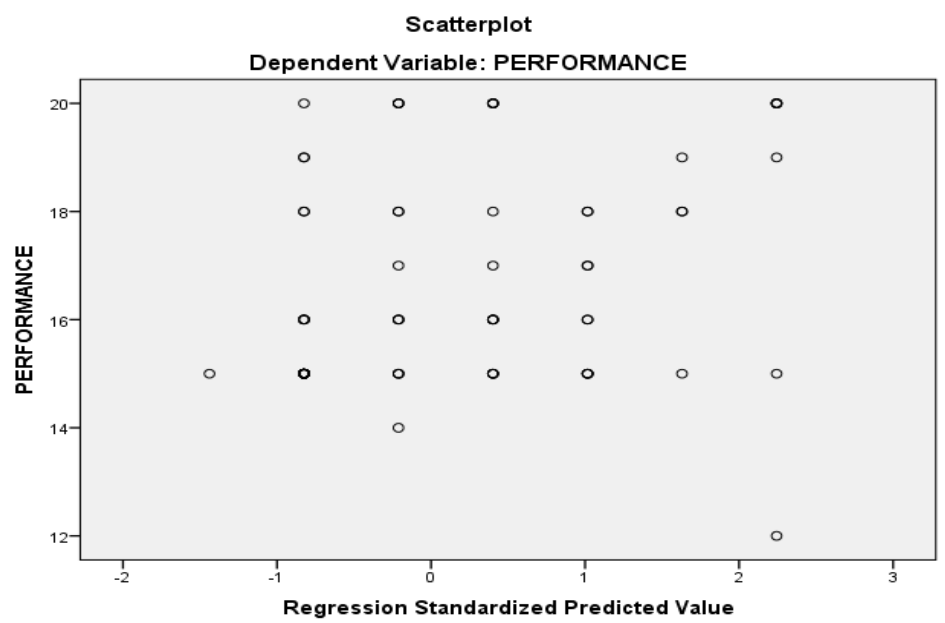

Gambar 2. Uji Heteroskedastisitas

Sumber: Pengolahan data, 2017

Gambar 2. dapat diketahui terjadi heteroskedastisitas karena penyebaran titik-titik data berbentuk pola. Data dapat dikatakan tidak terjadi heteroskedastisitas jika titik-titik menyebar di atas dan di bawah atau di sekitar 0, titik-titik data tidak mengumpul hanya di atas dan di bawah saja, penyebaran titik-titik data tidak membentuk pola bergelombang melebar kemudian menyempit dan melebar kembali, dan penyebaran titiktitik tidak berpola.

\subsection{Uji Korelasi}

\section{Uji Korelasi Berganda}

Korelasi berganda merupakan alat untuk mengukur hubungan atau tingkat asosiasi antara variabel-variabel bebas (X) terhadap variabel terikat (Y) secara simultan. Uji korelasi berganda dapat di lihat pada Tabel 9. 
Tabel 9. Uji Korelasi Berganda

\begin{tabular}{|c|c|c|c|}
\hline \multicolumn{4}{|c|}{ Uji Korelasi Berganda (Method Forward) } \\
\hline R & R (Square) & F & Sig. \\
\hline 0,371 & 0,138 & 14,048 & 0,000 \\
\hline
\end{tabular}

Sumber: Pengolahan data, 2017

Tabel 9. diketahui kofesien korelasi berganda variabel motivasi kerja (X2) terhadap kinerja karyawan $(\mathrm{Y})$ sebesar $(\mathrm{R})=0,371$ berarti variabel motivasi kerja mempunyai hubungan yang lemah positif terhadap kinerja karyawan. Koefisien determinasi (R Square) $=0,138$ atau 13,8\% artinya variabel motivasi kerja hanya dapat menjelaskan perubahan tingkat kinerja karyawan sebesar 13,8\% sedangkan $86,2 \%$ dijelaskan oleh variabel lainnya. Diperoleh F hitung sebesar 14,048 dan signifikansi $=0,000$ atau $0 \%<5 \%$ (a) maka hubungan yang lemah positif tersebut signifikan.

2. Korelasi Parsial

Hasil uji korelasi parsial dapat di lihat pada Tabel 10.

Tabel 10. Uji Korelasi Parsial

\begin{tabular}{|c|c|c|}
\hline \multicolumn{3}{|c|}{ Uji Korelasi Parsial } \\
\hline Variabel & Sig. & R \\
\hline Pelatihan (X1) & 0,056 & 0,203 \\
\hline Motivasi Kerja (X2) & 0,006 & 0,287 \\
\hline
\end{tabular}

Sumber: Pengolahan data, 2017

Tabel 10. diketahui besarnya koefisien korelasi parsial pelatihan (X1) dan kinerja karyawan (Y) dengan variabel pengontrol motivasi kerja (X2) sebesar 0,203 dengan signifikan 0,056 atau 5,6\%. Dapat disimpulkan tidak terdapat hubungan yang signifikan pelatihan (X1) terhadap kinerja karyawan (Y) dan memiliki hubungan yang lemah positif. Sedangkan koefisien korelasi parsial motivasi kerja (X2) dan kinerja karyawan (Y) dengan variabel pengontrol pelatihan (X1) sebesar 0,287 dengan signifikan 0,006 atau 6\%. Dapat disimpulkan terdapat hubungan yang signifikan motivasi kerja (X2) terhadap kinerja karyawan (Y) dan memiliki hubungan yang lemah positif. 


\section{SIMPULAN}

1. Pengaruh pelatihan dan motivasi kerja terhadap kinerja karyawan secara simultan dengan persamaan linier berganda yaitu $\mathrm{Y}=9,233+0,434 \mathrm{X} 2$ tidak memiliki pengaruh yang signifikan jika dilakukan secara bersamasama. Karena hanya variabel motivasi kerja yang memiliki pengaruh terhadap kinerja karyawan, sedangkan variabel pelatihan tidak memiliki pengaruh terhadap kinerja karyawan.

2. Secara parsial tidak terdapat pengaruh yang signifikan pelatihan terhadap kinerja karyawan dan mempunyai hubungan yang lemah positif. Besarnya sig pelatihan yaitu $0,056>0,05$ yang menyebabkan tidak terjadinya pengaruh pelatihan yang signifikan terhadap kinerja karyawan. Sedangkan pengaruh motivasi kerja terhadap kinerja karyawan memiliki pengaruh yang signifikan dan mempunyai hubungan yang lemah positif. Besarnya sig motivaasi kerja yaitu $0,000<0,05$ yang menyebabkan adanya pengaruh motivasi kerja yang signifikan terhadap kinerja karyawan. variabel motivasi kerja hanya dapat menjelaskan perubahan tingkat kinerja karyawan sebesar 13,8\% sedangkan 86,2\% dijelaskan oleh variabel lainnya.

\section{DAFTAR PUSTAKA}

Aruan, D.A., 2013, Pengaruh Pelatihan Kerja dan Motivasi Terhadap Kinerja Karyawan PT Sucofindo (Persero) Surabaya, Universitas Negeri Surabaya, Vol. 1, No. 2.

Sujarweni, V.W., 2014, SPSS Untuk Penelitian, Pustaka Baru Perss, Yogyakarta.

Sunyoto, D., 2015, Penelitian Sumber Daya Manusia: Teori, Kuesioner, Alat Statistik, dan Contoh Riset, CAPS (Center of Academic Publishing Service), Yogyakarta.

Susanty, A., Baskoro, S.W., 2012, Pengaruh Motivasi Kerja dan Gaya Kepemimpinan Terhadap Disiplin Kerja Serta Dampaknya Pada Kinerja Karyawan (Studi Kasus Pada PT PLN (Persero) APD Semarang), Universitas Diponegoro, Vol. 8, No. 2.

Yani, M., 2012, Manajemen Sumber Daya Manusia, Mitra Wacana Media, Jakarta. 